\title{
Primary health eye care knowledge among general practitioners working in the Cape Town metropole
}

\section{LM Van Zyl MBChB, DipOphth(SA), N Fernandes MBChB, G Rogers MBChB, DipOphth(SA), DCH(SA) \& N Du Toit MBChB, DipOphth(SA), FRCS(Ed), FCOphth(SA), MMed}

To cite this article: LM Van Zyl MBChB, DipOphth(SA), N Fernandes MBChB, G Rogers MBChB, DipOphth(SA), DCH(SA) \& N Du Toit MBChB, DipOphth(SA), FRCS(Ed), FCOphth(SA), MMed (2011) Primary health eye care knowledge among general practitioners working in the Cape Town metropole, South African Family Practice, 53:1, 52-55, DOI: 10.1080/20786204.2011.10874060

To link to this article: http://dx.doi.org/10.1080/20786204.2011.10874060

а (c) 2011 SAAFP. Published by Medpharm.

Submit your article to this journal $\square$ 


\title{
Primary health eye care knowledge among general practitioners working in the Cape Town metropole
}

\author{
Van Zyl LM, MBChB, DipOphth(SA) \\ Fernandes $\mathrm{N}$, MBChB \\ Rogers G, MBChB, DipOphth(SA), DCH(SA) \\ Du Toit N, MBChB, DipOphth(SA), FRCS(Ed), FCOphth(SA), MMed \\ Division of Ophthalmology, Groote Schuur Hospital, Cape Town, South Africa \\ Correspondence to: Dr Lourens van Zyl, e-mail: lourensvz4@gmail.com \\ Keywords: survey; ophthalmology; general practitioners
}

\section{Abstract}

S Afr Fam Pract 2011;53(1):52-55

Aim: The main purpose of this study was to determine whether general practitioners (GPs) in the Cape Town metropole have sufficient knowledge to diagnose and treat primary care ophthalmic conditions correctly, and to assess their own perceptions of their levels of knowledge. Secondary objectives included identifying the need for courses to improve the ophthalmic knowledge of GPs and assessing whether there is a need to revise the undergraduate curriculum in ophthalmology in general.

Method: A cross-sectional survey was done. A questionnaire of 10 primary care level ophthalmology questions, including a self-assessment section, was sent to each of 140 randomly chosen GPs in Cape Town.

Results: A response rate of $79.2 \%$ was obtained. Respondents included graduates from all eight medical schools in South Africa. Most of the responding GPs were practising for more than 10 years (78.2\%). The mean test score was $52.5 \%$ (standard deviation [SD]: 22.2). The mean self-rating was $51.9 \%$ (SD: 14.5). There was no statistically significant difference between the test score and the self-rating score $(p=0.5840)$. Responding GPs felt that there is a need for ophthalmology up-skilling courses and $99.9 \%$ of them would attend such courses. Also, $82 \%$ of GPs felt that primary care doctors, not optometrists, should deliver primary eye care.

Conclusion: GPs appear to lack sufficient knowledge to manage primary health eye care problems, presumably due to a lack of adequate training in the field. Clinical up-skilling courses are needed to improve core knowledge in ophthalmology.

(P) Peer reviewed. (Submitted: 2010-05-10, Accepted: 2010-06-18). ๑ SAAFP

\section{Introduction}

A significant percentage of patients seen at the primary health care level (district clinics, community health centres, district hospital outpatient clinics, private practice) have problems with their eyes. In the University of Cape Town (UCT) undergraduate medical curriculum, only two weeks in the fifth year of the course are allocated to ophthalmology. This is considered to be inadequate by many ophthalmologists. A significant proportion of the cases seen at the emergency section of the eye clinic at Groote Schuur Hospital (GSH) are considered to have been incorrectly evaluated by the referring primary care physician (personal experience).

The problem of inadequate ophthalmology training and inadequate eye care by primary health care doctors is not unique to Cape Town. Studies in the UK, Australia, New Zealand and USA have identified a similar situation. ${ }^{1-6}$ Workshops to improve primary health clinical and diagnostic skills in ophthalmology have been found to be effective in improving the skills of primary care physicians in these countries. ${ }^{7,8}$ In South Africa, we are not aware of any such courses to enhance the ophthalmic skills of the primary care doctor. Most South African general practitioners (GPs) are forced to rely on the knowledge acquired from their limited undergraduate training to practise primary care ophthalmology for the rest of their professional careers.

It is estimated that almost $50 \%$ of all patients seen at Groote Schuur Hospital's 'walk-in' eye clinic are referrals from GPs in private practice. There is also an impression that there are too many misdiagnosed eye cases and incorrectly treated blinding ophthalmic conditions being referred to $\mathrm{GSH}$. The aim of the study was identify whether GPs in the Cape Town metropole have sufficient knowledge to correctly diagnose and treat primary care ophthalmic conditions and to assess their own perceptions of their levels of knowledge. The objective was to identify the need for courses to improve 
the ophthalmic knowledge of GPs and to identify gaps in the teaching of undergraduate medical students.

\section{Methods}

A sampling frame of all the GPs working in private practice in the Cape Town metropole was compiled from the database of the Board of Healthcare Funders (BHF) of South Africa. A sample of $140 \mathrm{GPs}$ was randomly selected from 314 GPs registered with the BHF as working in the Cape Town Metropole. GPs were all informed telephonically that they had been selected to take part in a study and were requested not to refer to textbooks when answering the questionnaire. GPs were not informed that the questions would regard ophthalmology. Ethical approval to conduct this study was obtained from the Ethics Department of UCT, Groote Schuur Hospital.

A questionnaire was posted to each of the selected GPs, with a stamped and addressed return envelope. The questionnaire consisted of two parts. The first part comprised 10 questions testing primary eye care levels of knowledge and skills. The questions were chosen from the question bank of the UCT Division of Ophthalmology fifthyear undergraduate curriculum, as a standard questionnaire in the assessment of generalist knowledge is not available in the literature. This was done in conjunction with the UCT ophthalmology course convenor. The questions were in multiple-choice format and covered clinically orientated topics that undergraduate students are expected to know, including clinical scenarios that would present to a GP in a generalist practice. The correctly answered questions were totalled for each GP and the mean score of the subjects' knowledge was then calculated. Ten clinical questions were asked, for which each had four possible answers, only one of which was the correct answer. They were:

1. A patient presents with a unilateral, painful, red eye with hazy vision, photophobia and a small pupil. What is the likely diagnosis?

2. How do you diagnose acute angle-closure glaucoma before referral to an ophthalmologist?

3. Is the initial treatment of uveitis that of chloramphenicol (antibiotic) ointment?

4. What is the clinical sign on fundoscopy of proliferative diabetic retinopathy?

5. A young patient presents to you with a history of long-standing blurred vision. The vision in both eyes improves dramatically with pinhole. The following would be the most appropriate (select from four options):

6. In a patient who presents with headache and a complete third nerve palsy of recent onset, with pupil involved, what would the most likely cause be?

7. How do you test for a relative afferent pupillary defect and what does it signify?

8. How important is the use of topical dexamethasone (a steroid) for a herpes simplex dendritic ulcer?

9. A mechanic presents with painful red eyes about six hours after welding, with no visible foreign body on the cornea. What is your next step?

10. A patient sees flashing lights and floaters. What is the patient in danger of developing?

The second part consisted of eight questions where the subjects were asked, among others, to assess their own impressions of their levels of knowledge. A mean self-rating score of the subjects' knowledge was then worked out. The questionnaire also addressed the issue of whether GPs felt that there is a need for courses in ophthalmology to up-skill the practitioner. The questions were:

1. On a scale of 1 to $10(1=$ very poor; $10=$ excellent $)$, how would you rate your ophthalmology knowledge?

2. What percentage of patients with an eye problem consults you at your practice?

3. Do you think it is necessary that CPD courses be held to increase GPs' knowledge of ophthalmology?

4. Would you attend such a course?

5. Do you think a GP or an optometrist should be responsible for primary eye care?

6. Are you male or female?

7. For how long have you been in private general practice?

8. At which university did you complete your MBChB/ MBBCh/MBBS?

\section{Results}

Of the 140 questionnaires that were posted to randomly chosen GPs, there were 111 responses, a response rate of $79.2 \%$. Most of the respondents were graduates from the University of Cape Town (35.5\%) and the University of Stellenbosch (34.6\%); however we did have responses from graduates of all eight medical schools in South Africa. Of the respondents, $54 \%$ were male and $46 \%$ female. Most of the responding GPs had been in general practice for more than 10 years $(78.2 \%)$ and only $21.8 \%$ of respondents had been in practice for a shorter period. In $98 \%$ of practices, GPs estimated that the number of patients seeking eye care was between $10 \%$ and $20 \%$ of all patients.

In the ophthalmology core knowledge test, the mean test score was $52.5 \%$ (SD: 22.2). When GPs were asked to rate their own knowledge in ophthalmology, more than half $(58.3 \%)$ of the respondents rated their knowledge at 5 or 
Figure 1: Box plot of self-rating and test scores

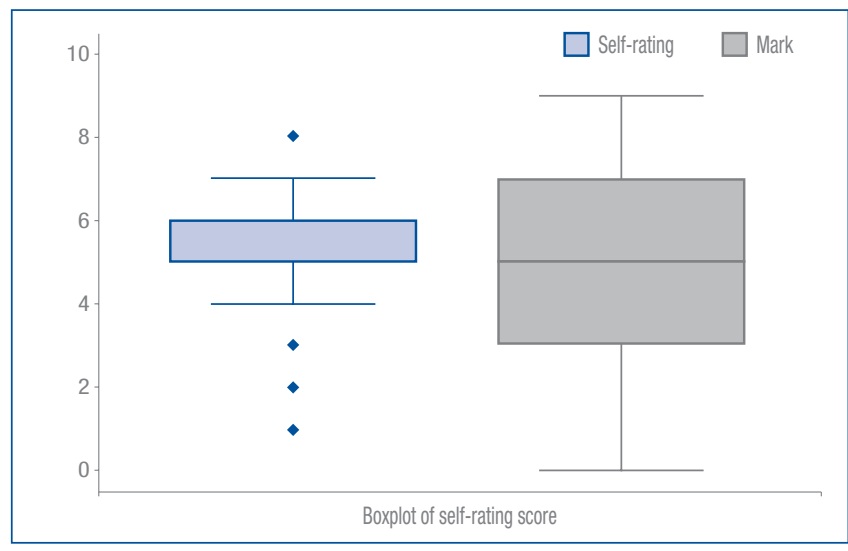

less (on a scale of 1 to 10 ) and only $41.7 \%$ gave themselves a score of 6 or more. The mean self-rating was $51.9 \%$ (SD: 14.5). There was no statistically significant difference between mean self-rating and test scores ( $p=0.5840$ ). These findings are shown in Figure 1.

The number of years in practice did not seem to be of any significance in the clinical knowledge part. GPs were divided into groups of those having been in practice for fewer than 10 years, between 10 and 20 years, and for more than 20 years. Most of the respondents were in the latter two categories (38\% and $40 \%$ ), with only $22 \%$ being in practice for fewer than 10 years. The average score in each category was $50.2 \%, 52.7 \%$ and $54.6 \%$, respectively. There was no statistical significant difference in the scores of the three categories.

An alarming finding in the core knowledge testing was that almost $10 \%$ of respondents would treat herpetic corneal ulcers with topical steroids. Fifty per cent of those were in GP practice for fewer than 10 years. There was no statistical significance ( $p=0.1659$ ), but the clinical significance is that younger GPs are not as aware of the dangers of topical steroids in herpetic ulcer disease as their more experienced counterparts. This treatment is usually completely contraindicated and may play a significant role in iatrogenically induced blindness.

All the GPs that responded to the questionnaire thought that ophthalmology up-skilling courses should be made available in South Africa and $99.9 \%$ suggested that they would attend such courses. Despite the finding that both primary care ophthalmology knowledge and self-rating of knowledge was poor, $82 \%$ of GPs felt that they themselves or medical officers, rather than optometrists, should deliver primary eye care.

\section{Discussion}

At the Midland Eye Hospital in Birmingham, GP referrals to an eye emergency unit were evaluated. Analysis revealed that $50-70 \%$ of referrals did not constitute urgent conditions and could have been better managed at secondary level outpatient clinics. ${ }^{5}$ In a study conducted in the UK to assess the referral pattern to ophthalmologists, it was found that optometrists and GPs were the leading referrers from primary health care units. Optometrists' main reason for referral was cataracts, while GPs referred more eyelid, tear duct and conjunctival conditions. The study found that agreement with ophthalmological diagnosis was high for both groups of primary care practitioners, but that concurrence of referral reason with the ophthalmological diagnosis of glaucoma was lower for GPs than for optometrists. ${ }^{9}$ The accuracy of testing and diagnosing diabetic retinopathy was studied in the US and it was found that family physicians were fairly accurate in screening patients for diabetic retinopathy. ${ }^{4}$

In this study, GPs rated their ophthalmology knowledge to be just over $50 \%$ (which can be regarded as inadequate), yet GPs are often the 'first port of call' for many ophthalmic patients. GPs estimated that $10-20 \%$ of all their patients had eye problems, and the question therefore arises: in light of the poor test and self-rating results, are GPs administering the correct treatment to the patients that they assess? Answers to one of the questions in this study indicated that almost $10 \%$ of respondents would treat herpetic corneal ulcers with topical steroids, which is absolutely contraindicated. This raises the question as to whether ophthalmology undergraduate training is adequate and whether the curriculum needs to be revised.

Ophthalmology is not only a neglected subject in the undergraduate curriculum in South Africa. In the USA, up to $70 \%$ of medical schools do not require rotation through ophthalmology for graduation. ${ }^{1}$ A study was conducted in Otago (New Zealand) to assess the ophthalmology curriculum, in which ophthalmologists, optometrists, and GPs were asked to give input as to what important topics should be covered in the undergraduate medical curriculum. The overall responses of the three participant groups were similar and agreed favourably with what was included in the current curriculum. The ability to measure visual acuity (97\%), test pupillary reflexes (93\%), perform ophthalmoscopy (92\%) and assess visual fields (68\%) was regarded as 'important or essential' by the majority of respondents. Despite glaucoma being a major cause of blindness in the world, only $53 \%$ of respondents considered the ability to diagnose chronic open-angle glaucoma as important. The respondents stressed the importance of diagnosing predominantly anterior segment disease, which 
contrasted with the traditional bias towards the teaching of ophthalmoscopy and posterior segment disease. The majority of respondents noted the importance of graduating medical students being able to treat conjunctivitis, styes, blepharitis, corneal abrasions and corneal/conjunctival foreign bodies, which are also represented in current curricula. ${ }^{2}$

The effectiveness of undergraduate teaching in ophthalmology was studied at the Bristol Eye Hospital. Almost $90 \%$ of the respondents regarded their ophthalmology knowledge to be inadequate, and the use of an ophthalmoscope was regarded as being very difficult. However, $83 \%$ of respondents who attended postgraduate courses in ophthalmology regarded their knowledge of primary care ophthalmology as being adequate. ${ }^{3}$ Glaucoma recognition, treatment and referral seem to be universal problems. In a study conducted among GPs in Brisbane, Australia, only $15 \%$ of GPs were satisfied with their knowledge and skills in diagnosing glaucoma. Yet, more than $57 \%$ of them felt that GPs should play an active role in the treatment of glaucoma. ${ }^{6}$

It is clear from the above that most GPs are lacking in adequate levels of training, confidence and skills in ophthalmology. We need to establish what should be done to improve the knowledge of GPs so that they can render better primary eye care. GPs in Brisbane were recruited to participate in a clinical up-skilling intervention which was delivered over an eight-week period. After the up-skilling intervention, the proportion of GPs able to accurately recognise glaucomatous disc damage on clinical assessment rose from $24.0 \%$ to $54.2 \%$. The proportion able to accurately recognise diabetic fundal disease on clinical assessment rose from $30.8 \%$ to $54.1 \%$. The ability to recognise fundal disease on slide presentations rose on average from $27.1 \%$ to $67.5 \% .^{7}$ It appears that, in order to improve the skills and competence of GPs in ophthalmology, up-skilling workshops appear to be a definite option.

Collaboration between the Royal Australian Colleges of General Practice and Ophthalmology was carried out to set up workshops for the enhancement of ophthalmic skills over a range of important ocular examination and procedural areas. These workshops were run in eight Queensland divisions of general practice. Between two and 10 local ophthalmologists in each divisional area were involved either in the workshop programme or in the recruitment of patients for the patient assessment module. Workshops were run on weekends and included modules on vision testing and disease screening in children and adults, ophthalmoscopy, assessment for glaucoma and diabetic retinopathy, incision of chalazions, removal of corneal foreign bodies, ocular first aid, implementing eye assessment in busy general practices and a patient assessment clinic. ${ }^{8}$ All the GPs that responded to our questionnaire thought that ophthalmology up-skilling courses should be made available and almost all of them felt that they would attend such courses.

It must be mentioned that the cross-sectional survey study design used here is fraught with weaknesses, but it should also be noted that the response rate of almost $80 \%$ is reasonably good. The fact that approximately $80 \%$ of GPs had been in practice for 10 years or more also reflects that experienced practitioners were involved. This study gives some insight into the problems of inadequate knowledge and skills present in primary health eye care which do need further investigation.

In conclusion, it is clear that GPs, in general, lack adequate knowledge in primary eye care. Most GPs rely on the knowledge acquired during their limited undergraduate training to practise primary care ophthalmology. Clinical upskilling courses appear to be a method that can equip our GPs with the knowledge and skills that they need to provide a better primary eye care service.

\section{References}

1. Higginbotham EJ, Rust G. Ophthalmology and primary care: partners in peril? Arch Ophthalmol 2008 May;126(5):727-8.

2. Ah-Chan JJ, Sanderson G, Vote BJ, Molteno AC. Undergraduate ophthalmology education survey of New Zealand ophthalmologists, general practitioners and optometrists. Clin Experiment Ophthalmol 2001 Dec;29(6):416-25.

3. Shuttleworth GN, Marsh GW. How effective is undergraduate and postgraduate teaching in ophthalmology? Eye 1997;11(Pt 5):744-50.

4. Gill JM, Cole DM, Lebowitz HM, Diamond JJ. Accuracy of screening for diabetic retinopathy by family physicians. Ann Fam Med 2004 May-Jun;2(3):218-20.

5. Kheterpal S, Perry ME, McDonnell PJ. General practice referral letters to a regional ophthalmic accident and emergency department. Eye 1995;9(Pt 6 Su):67-9.

6. Jackson C, Hirst L. Brisbane GPs' perceptions of screening for primary openangle glaucoma. Aust N Z J Ophthalmol 1995 Aug;23(3):179-81.

7. Jackson C, Hirst L, Ambler JA, Battistutta D. GPs and eye skills. A brave new world? Aust Fam Physician 1997 Apr;26(4):409-11, 413-5.

8. Jackson C, De Jong I, Glasson W. Royal Australian College of Ophthalmologists and Royal Australian College of General Practitioners National GP Eye Skills Workshops: colleges and divisions re-skilling general practice. Clin Experiment Ophthalmol 2000 Oct;28(5):347-9.

9. Pierscionek TJ, Moore JE, Pierscionek BK. Referrals to ophthalmology: optometric and general practice comparison. Ophthalmic Physiol Opt 2009 Jan;29(1):32-40 